學 先 心生江

之生理が凡な松

しが學今 $乞 つ$ 本

$\tau$ 心史學右先

䆃 理 去問。生

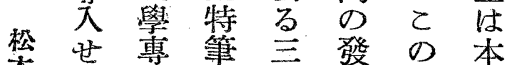

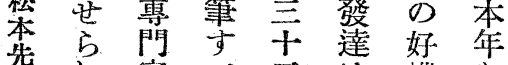

生れ家へ五は機老

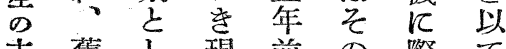

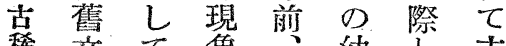

稀交て 像、幼し古

䦅學講で郎稚て 稀

壽部座亦明を松に

て 本老つ治時本達

館擔を兰代先せ

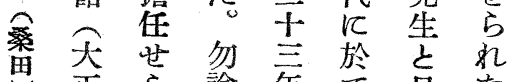

正部年て 日

○松注本の

震居先海先理で

飞方生準學乙

燒。歸 方 國 の

失元朝歸 の發に

乙良以朝學 達 祝

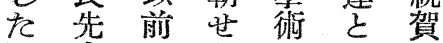

生飞方及江

のも・姏び就意

一凮當て 學て

隅飞時所說聊表

米唯謂を加守

あ國一賁 導考る

るにの驗大察を

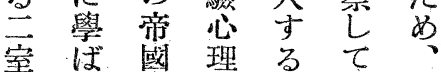

老叔大學見本

另後學老吾方誌

研儿㐫或、之輯

究所 $\mathrm{r}$ 葸老

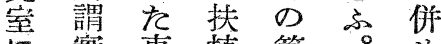

飞實東植第。。

一㗬驗亭蒂步論

ら理國机穴变

机學大た市集

标考學方名亭

併泣住松当

東 さ

松

心

本

理

先 松

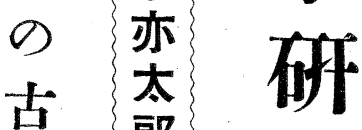

稀 㙛 哥

走

第

帝

國

大

學

桑

才

念 卷

論 第

文 五

集

is

輯

田

二

旮

四

芳

年

十

月

我物良星先先立 


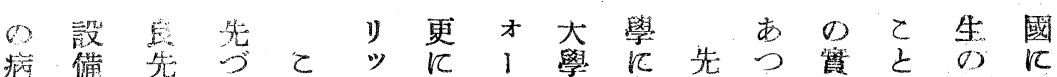

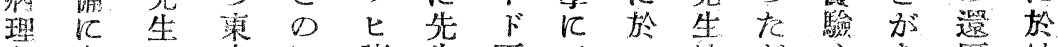

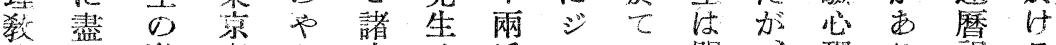

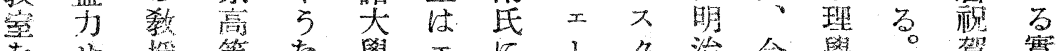

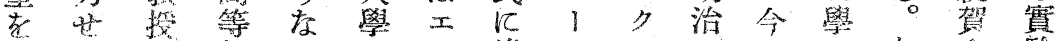

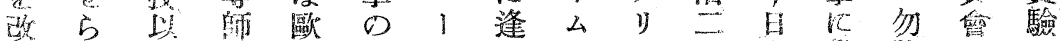

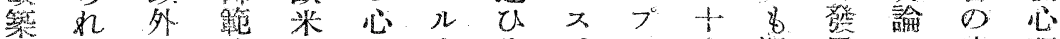

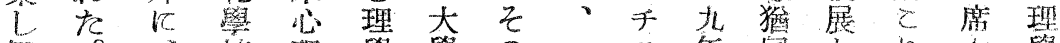

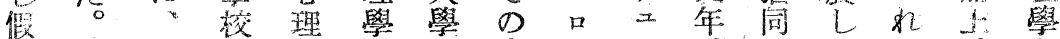

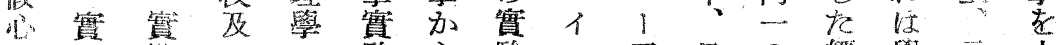
理 驗 びの 驗 ら 驗

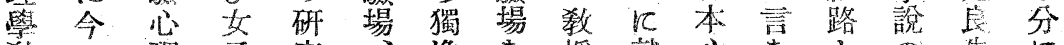

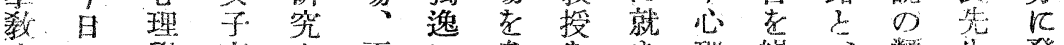

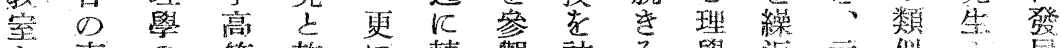

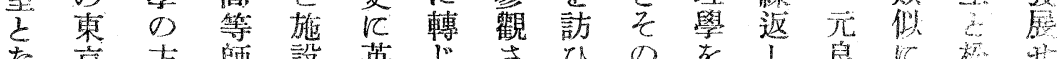

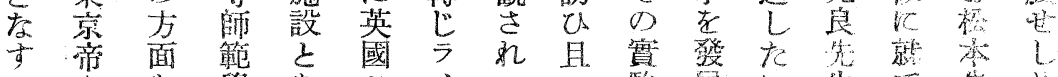

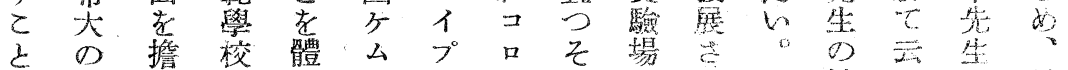

に心篦に得ブチンのに业

な理せ 教しりッビ實於や

b 學ら 授て $て$ ヒ $ア$ 驗て

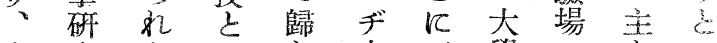

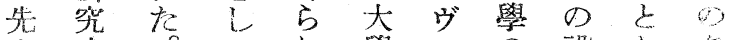

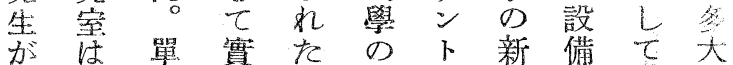

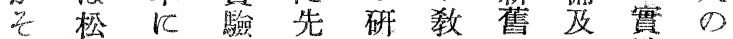

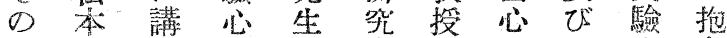

改先義琵は室に理研心負

築些學着老就學究理起

案の惯起名加實孛持

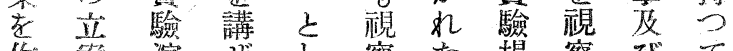

作笔演ぜし察た場察びて

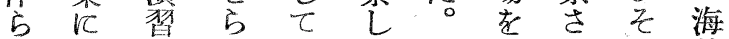

机存ばれて視狆の外

三丨加、の歸の察、研に

十 tb繼學朝他 L多究出 齐 8 で的さ伯力

年の存乘抱京林ツ! 步世

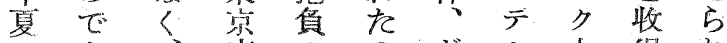

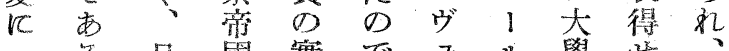

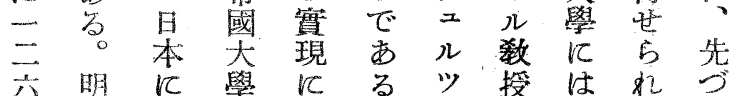

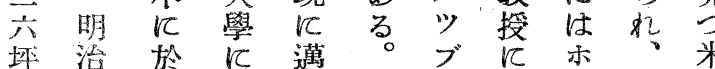

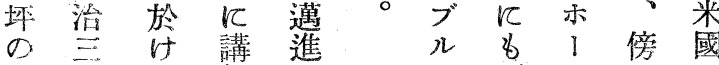

研干方師せ

究方實上它

室年驗しれ

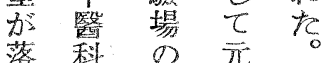

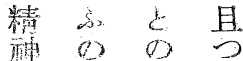

物 で 閶 實

理 係 驗

遙疗麦荎

加《孝

松西 0 篃

本洋 點 世

先 0 吕L

生赛 5 め

の 驗 見 5

蜜㐫てれ

驗、理、た

心學つの

理が正は

學: つ と 實

r $x$ 六

進七ル松

展市之本

しルヴ先

たのン生

乙 䆏 トだ

之䊖之市

孛 物 $00=$

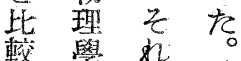

七面儿八片加秋

t⿱

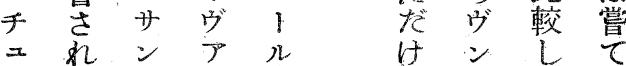

1 た
理 學 础 究 身 溇 第 五 童 


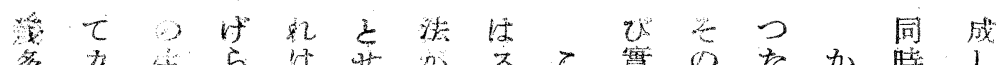

以

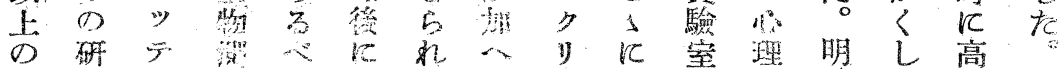

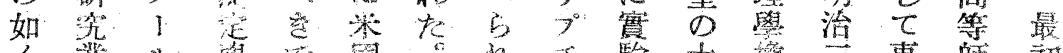

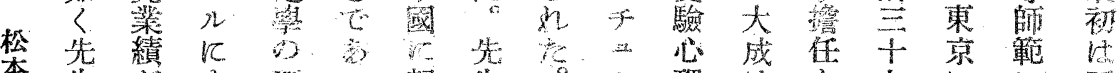

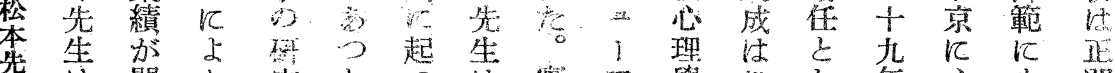

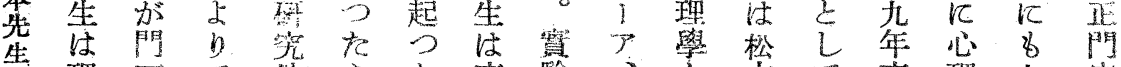

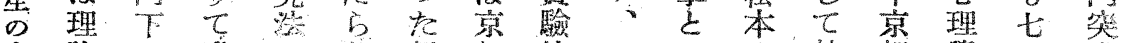
古論飞發に行都的方的先赴都學十虽

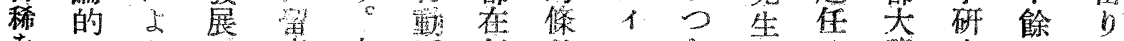

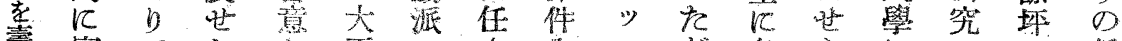

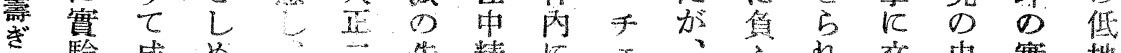

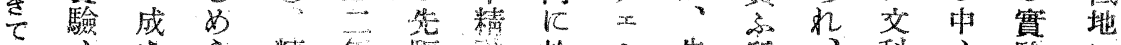

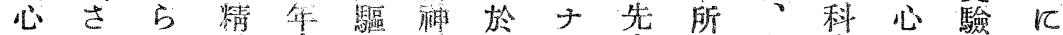

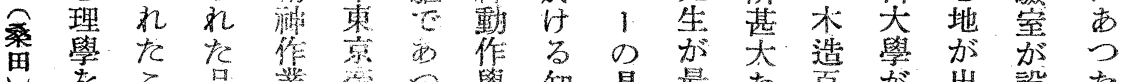

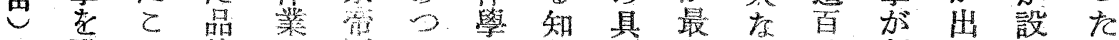

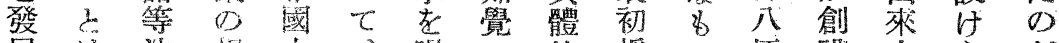

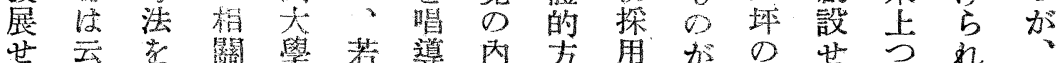

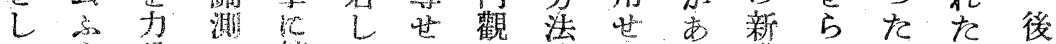

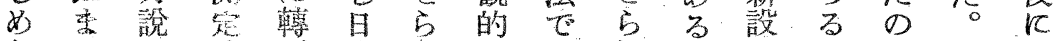

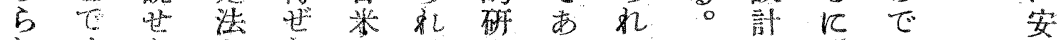

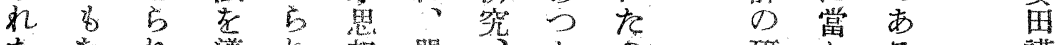

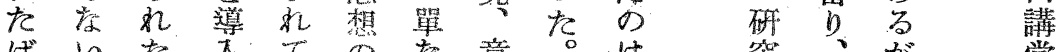

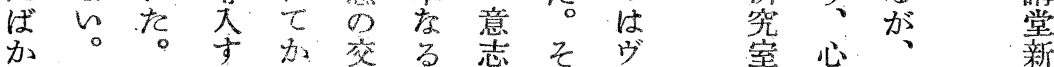

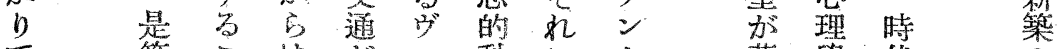

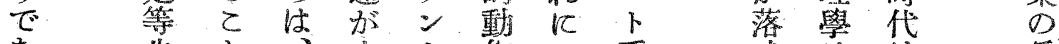
な 先之作名系成は地

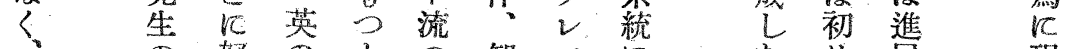

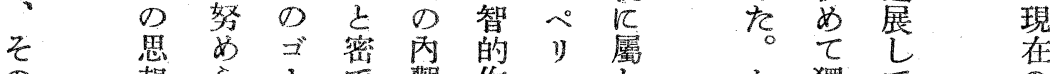

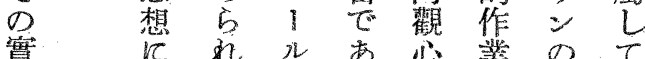

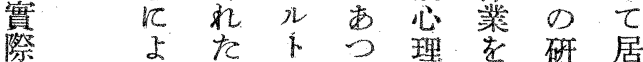
生b粚な究た 活文、在の方法が 指它

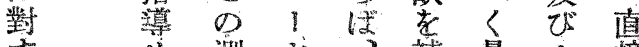
尔測†補量禾接

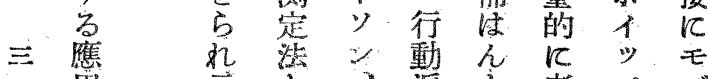
角示之派之考 プ ゙ 考唆聯 ス.

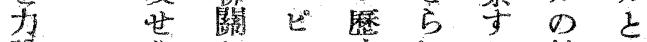
證 ら

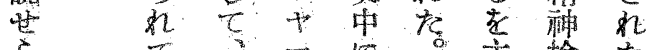

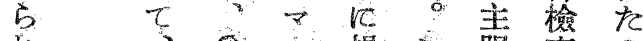

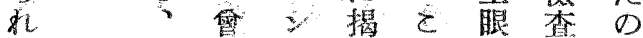




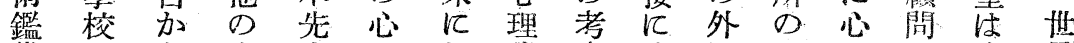
賞長 ら 文生理 於 學案先國一理之先界 の 廣 化 は 學て D 學 部學 生 太

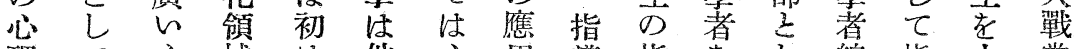
理て心域は他心用真指莸 $L$ 總指中當

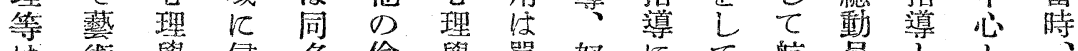

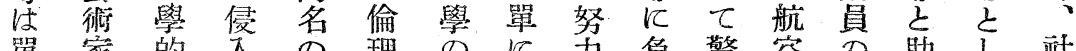

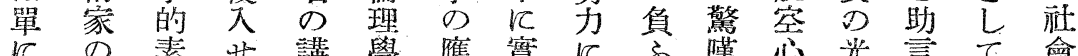

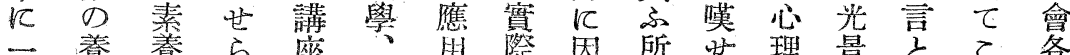
般成染れ老論五生つ多し部京索の方 畫に流た擔理 あ活て 犬めの接與種面

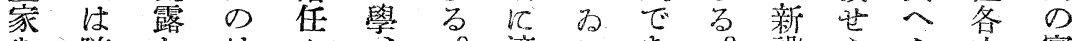

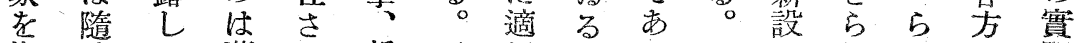

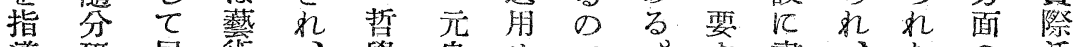

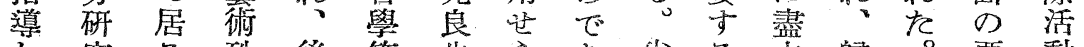

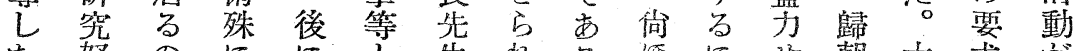

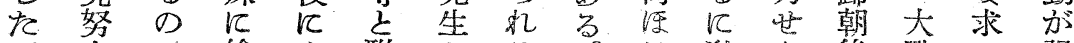
ば力で繪心 聯が方。旦敉 5 後戰に强

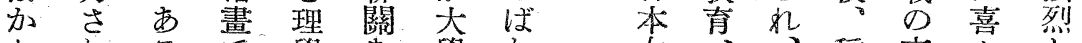

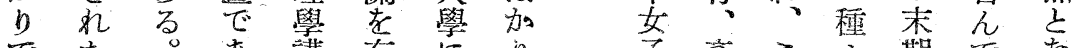

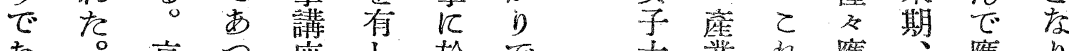
な 先 都た 擔 生帝。任々心采彪䈯方生た心 日の大穴の理、の信現面は理 本京呚れ方學精兒・せ海で學

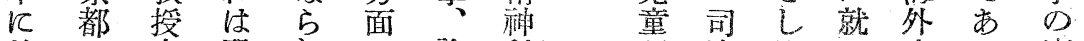
於時 在恐风の 諭科研法如て 出る 應 け代職くた論理學究令方廣胲。角

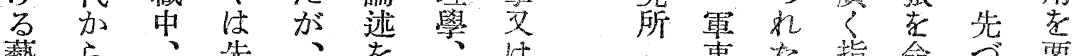

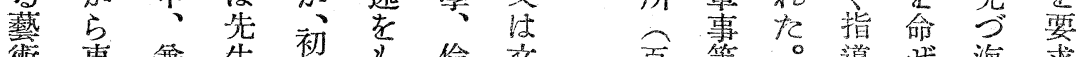

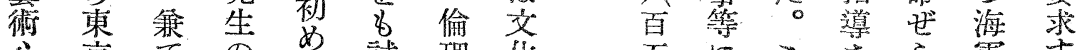
心京て の め試理华五にとさら軍士

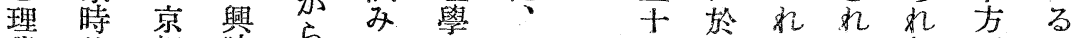

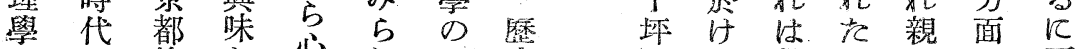

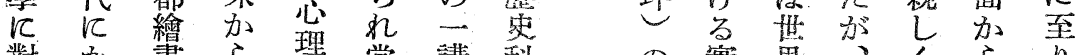

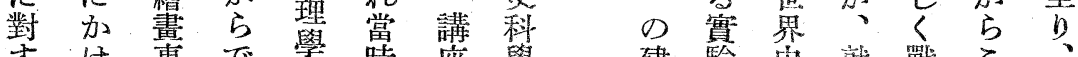

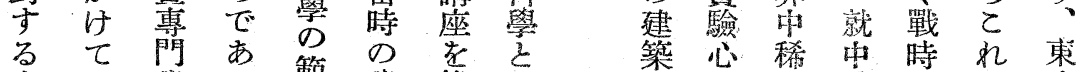

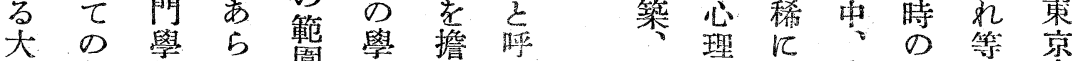
き文校 5 圍界任壮 設應見東米の帝

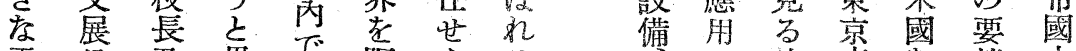

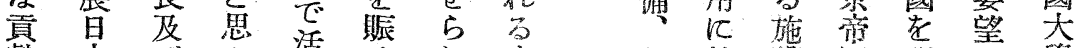

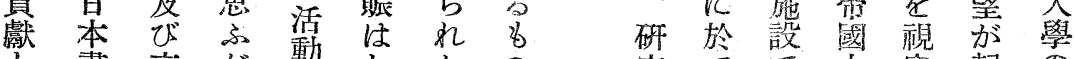
畫 京が 動

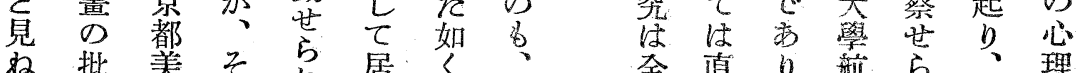

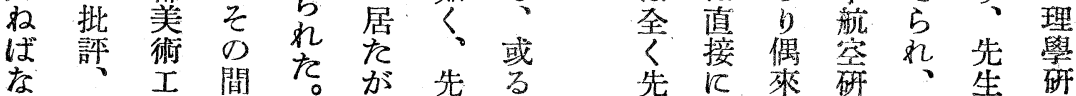
先闪來研、生研 


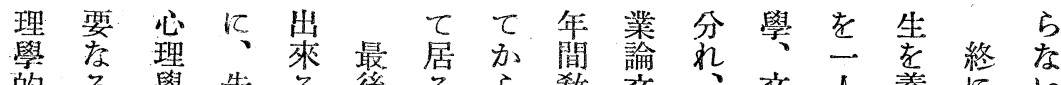

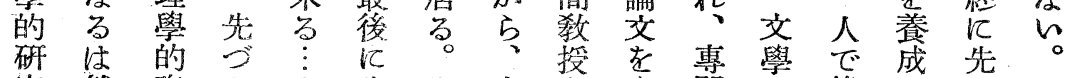
究然資必

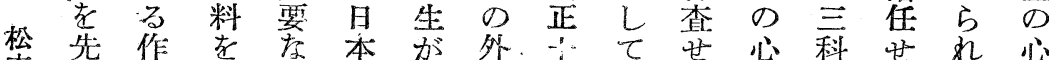
本進业發事人初、五心方理飞方瑟 告國法掘注の直年理れ學分れそ學

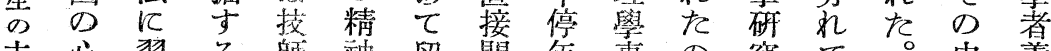
古心習る淿神留閽年重の究て。中養 稀 熟作的過學 接退攻で者居て三成 を學せ業、程さ識者あが宁の平に

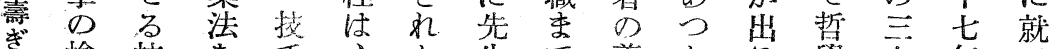

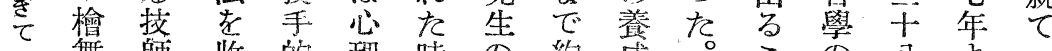

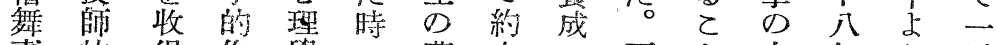

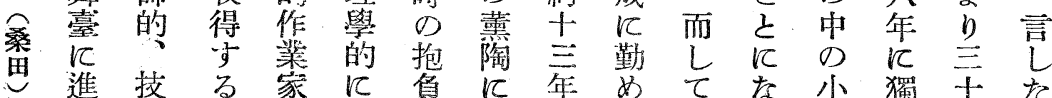

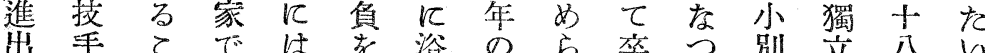

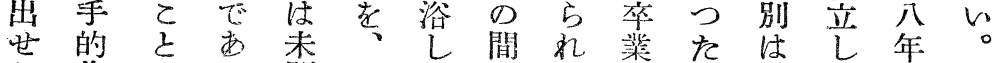

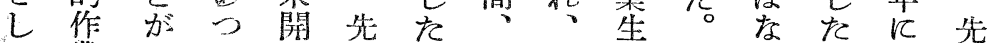
め業 日て 0 生心先約庄第加心亘生

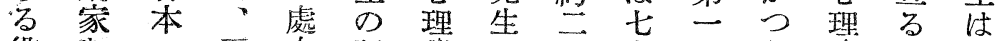
役をの而女語學の干人回た學—明 目多心地老徒指餘飞の方專學治 几數理多で借在導名過心、修年至

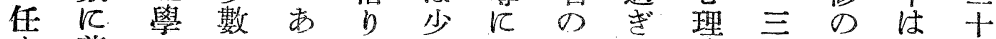

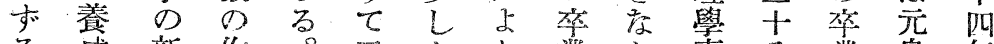
る成新作。云とり業加專八藻良年

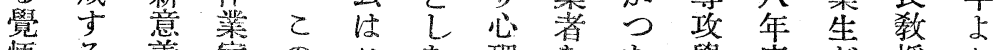
悟る義芜のざを理它た學度方授り

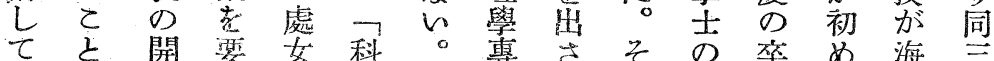

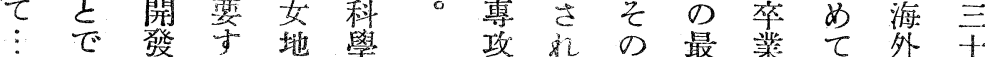

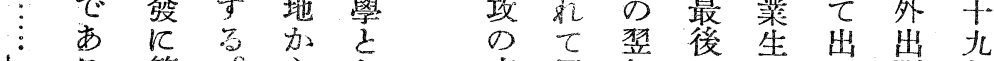

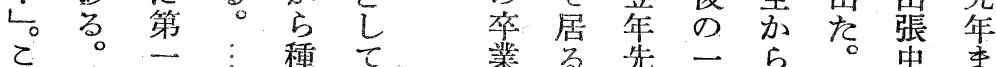

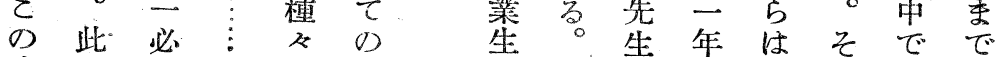

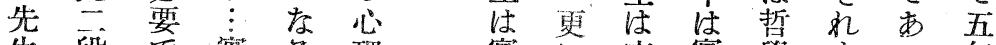

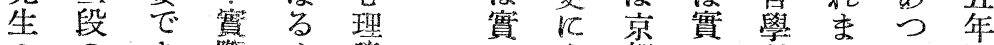
の あ際心學沈都学科でた間

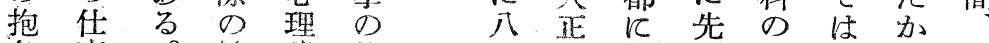

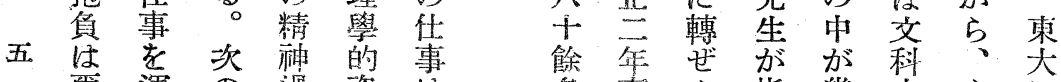

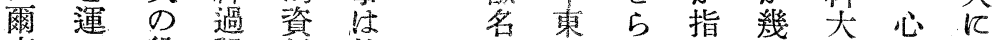

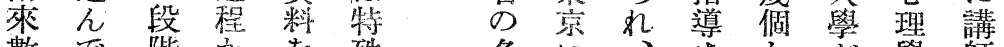
數で階方多殊 多、学學師

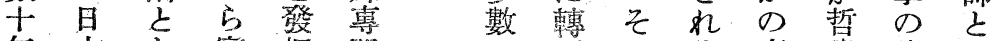

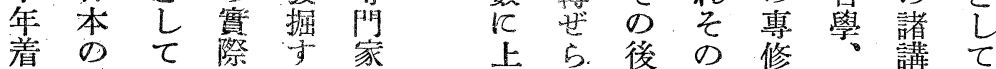

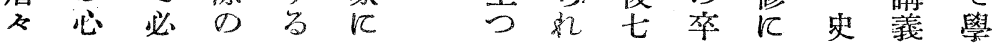




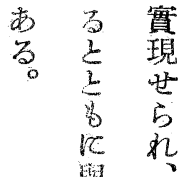

谥今心

p理

L 代 學

L W

乙 第 研

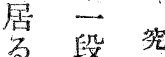

。

日 b 管

東第 飧

理 段

學 等

D移

己 9 、荤

日 心

學 理

i 學

谁は

展 多

振士。

江 濟

龂 \&

的

留 12

然第

D

is 0

3 域

面

嗝 進

校 7

业筧

慗進

㔍 便

t 對

$\therefore \quad$

6 取 
(From the Psychotogical Institute, Tokyo Imperial University)

\section{On the Commemoration of the Seventieth Birthday of Prof. M. Matsumoto}

by

\section{Y. Kuwata}

This number of the Journal is intended to commemorate the seventieth birthday of Prof. M. Matsumoto. He was born September 15, 1865. His academic career is as follows. Tokyo Imperial University, $1890-1898$, Bungakushi, Bungakuhakushi; Yale University, 1896-1898, Ph. D. ; University of Leipzig, 1898 - 1899. He was professor at Kyôto Imperial University, 19061913, at Tokyo Imperial University, 1913-1926, and now retired.

Psychology in Japan has made remarkable progress. There are large psychological institutes in the six Imperial, the two Bunrika and a few private Universities. We have also institutes for Child Study, Aeronautical Psychology and Labor Psychology. Many books and periodicals, and various researches are published both in Japanese and European languages, although most of them are written in Japanese and thus inaccessible to fore:gners. This great progress of the science is indebted mainly to the late Prof. Motoia and Prof. Matsumoto, especially to the latter.

Prof. Matsumoto has greatly developed Experimental Psychology and has improved or established laboratories in Japan. Many psychologists in this country are his pupils and their works were suggested or guided by him. $\mathrm{He}$ is now President of the Japanese Association of Psychology and taking an important part in the progress of the science. He has arrived now at the age of seventy, according to Japanese reckoning, which is called "Koki," i. e. "seldom attained from of old," and this is made a special occasion for celebration in our country. For commemorating it, a banquet was held on his birthday, September 15, and this issue of the Journal is dedicated to him in recognition of his distinguished services to Psychology. 